\title{
Correction to: Novel and de novo mutations in pediatric refractory epilepsy
}

Jing Liu' ${ }^{1,2}$, Lili Tong ${ }^{1,2}$, Shuangshuang Song ${ }^{3}$, Yue Niu ${ }^{1,2}$, Jun $\mathrm{Li}^{1,2}$, Xiu Wu $\mathrm{Wu}^{1,2}$, Jie Zhang ${ }^{4}$, Clement C Zai ${ }^{5}$, Fang Luo ${ }^{4}$, Jian Wu${ }^{4}$, Haiyin Li ${ }^{5}$, Albert HC Wong ${ }^{5}$, Ruopeng Sun ${ }^{1,2}$, Fang Liu ${ }^{2,5}$ and Baomin $\mathrm{Li}^{1,2^{*}}$

\section{Correction}

Following publication of the original article [1], the authors reported that one of the authors' names is spelled incorrectly. In this Correction the incorrect and correct author name are shown. The original publication of this article has been corrected.

Originally the author name was published as:

- Celement C. Zai

The correct author name is:

- Clement C. Zai

\section{Author details}

'Department of Pediatrics, Qilu Hospital of Shandong University, Jinan,

Shandong, People's Republic of China. ${ }^{2}$ Shandong University, Jinan,

Shandong, People's Republic of China. ${ }^{3}$ Qilu Children's hospital of Shandong

University, Jinan, Shandong, People's Republic of China. ${ }^{4}$ MyGenostics Inc.,

Beijing, People's Republic of China. ${ }^{5} \mathrm{Campbell}$ Family Mental Health Research

Institute, Centre for Addiction and Mental Health, University of Toronto,

Toronto, ON, Canada.

Received: 25 September 2018 Accepted: 25 September 2018

Published online: 16 October 2018

\section{Reference}

1. Liu, et al. Mol Brain. 2018;11(48). https://doi.org/10.1186/s13041-018-0392-5.

\footnotetext{
* Correspondence: 198962000693@sdu.edu.cn

'Department of Pediatrics, Qilu Hospital of Shandong University, Jinan,

Shandong, People's Republic of China

${ }^{2}$ Shandong University, Jinan, Shandong, People's Republic of China

Full list of author information is available at the end of the article
}

(c) The Author(s). 2018 Open Access This article is distributed under the terms of the Creative Commons Attribution 4.0 International License (http://creativecommons.org/licenses/by/4.0/), which permits unrestricted use, distribution, and reproduction in any medium, provided you give appropriate credit to the original author(s) and the source, provide a link to the Creative Commons license, and indicate if changes were made. The Creative Commons Public Domain Dedication waiver (http://creativecommons.org/publicdomain/zero/1.0/) applies to the data made available in this article, unless otherwise stated. 